\title{
Voltammetry of Solid Microparticles of Some Common Iron- and Copper-Iron Sulfide Minerals
}

\author{
Leon Stojanov ${ }^{1}$, Hristijan Vasilevski ${ }^{1}$, Petre Makreski ${ }^{1}$, Gligor Jovanovski ${ }^{2}$, Valentin Mirceski ${ }^{3,1}$ \\ ${ }^{1}$ Institute of Chemistry, Faculty of Natural Sciences and Mathematics, "Ss Cyril and Methodius" \\ University in Skopje, P.O. Box 162, 1000 Skopje, North Macedonia \\ ${ }^{2}$ Research Center for Environment and Materials, Macedonian Academy of Sciences and Arts, Bul. \\ KrsteMisirkov 2, 1000 Skopje, Republic of North Macedonia \\ ${ }^{3}$ Department of Inorganic and Analytical Chemistry, University of Lodz, Tamka 12, 91-403 Lodz, \\ Poland \\ *E-mail: valentin@pmf.ukim.mk, leonstojanov@pmf.ukim.mk
}

Received: 2 September 2021 / Accepted: 21 January 2022 / Published: 2 February 2022

\begin{abstract}
The electrochemistry of three common iron-sulfide minerals, i.e., pyrite $\left(\mathrm{FeS}_{2}\right)$, marcasite $\left(\mathrm{FeS}_{2}\right)$ and chalcopyrite $\left(\mathrm{CuFeS}_{2}\right)$, has been studied by voltammetry of solid microparticles for the purpose of obtaining typical voltammetric fingerprints for qualitative characterization and differentiation of mineral samples. Voltammetric patterns obtained under conditions of conventional cyclic voltammetry reflect the complex electrochemistry of the studied minerals, which have been immobilized on the surface of paraffin-impregnated graphite electrodes in the form of randomly distributed microparticles in contact with aqueous electrolytes. Voltammetric features depend strongly on the methodology of the cyclic voltammetry experiment, which can be conducted either by conditioning of the modified electrode at a given potential prior to the voltammetric scan or by commencing the voltammetry experiment from the open circuit potential. Highly structured, reproducible, specific, and self-normalized voltammetric patterns can be obtained under conditions of fast and sensitive square-wave voltammetry, which enables clear differentiation between the studied minerals, demonstrating that square-wave voltammetry can be used as a technique for in situ, fast and simple qualitative mineral characterization.
\end{abstract}

Keywords: iron-sulfide minerals, solid microparticles, voltammetric fingerprints, cyclic voltammetry, square-wave voltammetry

\section{$\underline{\text { FULL TEXT }}$}

(C) 2022 The Authors. Published by ESG (www.electrochemsci.org). This article is an open access article distributed under the terms and conditions of the Creative Commons Attribution license (http://creativecommons.org/licenses/by/4.0/). 